\title{
Incentive-based demand response: Case study
}

\author{
Respuesta de la Demanda Basado en Incentivos: Caso de Estudio \\ E. Rivas-Trujillo iD ; L. A. Arias-Barragán (iD) V. A. Hernández-Arias iD
}

\begin{abstract}
The present article discusses the development of a demand response system on a residential setting given that the proper management of energy resources by users can solve scarcity and energy reliability issues. The behavior of 1000 residential users is modelled through a peak control program based on economic and energy-related incentives. A demand response (DR) application is used where remuneration depends on scarcity pricing. The case study is shown including a mathematic algorithm and the application. The results obtained with the application exhibit a reduction of energy peaks, which translates into more efficient energy management which in turn is remunerated by scarcity pricing. It is concluded that the incentive-based DR program is viable both energy-wise and financially.
\end{abstract}

Index Terms - Aggregator; Demand Response (DR); Incentives; Optimization; Scarcity Pricing.

Resumen- El presente artículo pretende desarrollar la Respuesta de la demanda a nivel residencial, dado que con la adecuada gestión energética de los usuarios, se puede resolver problema de escasez y confiabilidad energética. Para esto se modela el comportamiento de mil usuarios residenciales al aplicar un programa de control de picos basado en incentivos energéticos y económicos por medio de un aplicativo de respuesta de la demanda (RD), donde la remuneración se realiza en función al precio de escasez. Se presenta el caso de estudio, el algoritmo matemático implementado y el aplicativo. En los resultados obtenidos en el aplicativo se tiene la disminución de los picos de energía, lo que representa una mejor gestión de energía, esta a su vez se ve remunerada por el precio de escasez, lo que permite concluir que el programa de RD basado en incentivos de control de picos es viable energética y económicamente.

Palabras claves: Agregador, Incentivos, Optimización, Precio de escasez, Respuesta de la demanda (RD).

This manuscript was sent on October 27, 2019 and accepted on June 12, 2020. This work has been developed by members of the GCEM (Electromagnetic Compatibility Group) research group at the Francisco José de Caldas District University.

E. Rivas Trujillo is now with University Distrital Francisco José de Caldas, Carrera 7 No 40-12 Bogotá D.C. (erivast@udistrital.edu.co).

L.A. Arias Barragan is now with University Autónoma de Colombia and University Distrital Francisco José de Caldas, Carrera 7 No 40-12 Bogotá D.C. (lariasb@ fuac.edu.co)

V. Hernandez Arias is now with Technological School Central Technical Institute, Calle 13 No 16-74 Bogotá D.C.( vahernandeza@itc.edu.co)

\section{INTRODUCTION}

$\mathrm{H}$ ALFWAY through 2016, Colombia suffered harsh consequences from the climatic event known as the El Niño phenomenon. This recurring weather pattern implies changes in temperature of waters in Central and Eastern regions of the Pacific tropic, directly affecting the distribution of precipitations in tropical areas [1]. This phenomenon caused droughts in the reservoirs of the country and led to an energetic crisis, prompting the "apagar-paga" campaign [2] (in Spanish, "it pays off to turn off”) based on incentives and penalizations for commercial and residential users to manage energy demands. It is expected that the demand response program improves the energy management to mitigate the aforementioned problems.

Demand response (DR) is defined as a set of strategies seeking to reduce the demand-related peaks from different participants of the energy market through the use of incentives or penalizations [3], [4], [5], [6]. A review of the scientific literature shows that the demand response of the residential sector based on incentives is a viable solution for the electrical system while handling scarcity issues and reducing demandrelated peaks [7], [8]. Each user can contribute with a determined amount of manageable power [9], [10], [11] that he/she is willing to unplug or reduce during certain hours of the day. This depends on a set of requirements given by the network operator, distributor or demand aggregator [12].

In [13], the integration of residential DR as an efficient strategy to balance the offer and demand of energy is studied. The authors in [14] present control and automation models suitable for users. In [15], it is proposed that the design of DR programs includes a multi-agent system with an aggregator that sets rules for users. The article in [16] shows that smart grids combined with distributed generation allow a complete integration with users through proper automation. The establishment of agreements in the form of 'disconnection contracts' leads to a stable power disconnection offer [17]. Demand peaks are also reduced compared to price-based DR [4], [18], translating into economic benefits for energy distributors since energy in peak hours is more expensive in both in terms of price and the environment. The latter is related to the activation of thermal power plants to cover the excess in demand. 
A case study is presented that serves as an example of the applicability of the DR resources based on incentives, compensated by using the scarcity pricing mechanism in the presence of demand-related peaks. It is proposed to unplug a share of the manageable power from 1000 residential users of middle income in the city of Bogotá, Colombia. A software application is developed that assesses the energy consumption per hour and the behavior of the global demand curve of users participating in DR incentive-based peak control services within a distribution network. The application can calculate the global cost of the energy not consumed by users and determine the shape of the consumption curve once the DR strategy is activated.

\section{Methodology}

Fig. 1 represents a block diagram of the methodology used for the development of the case study. In first place, a conceptual framework of DR programs is defined in terms of peak demand control, scarcity pricing, user demand curve and manageable load. In second place, the case study is described as well as the variables and the mathematic reasoning behind the application used to simulate the DR program. The results and their analysis are shown in the final section.

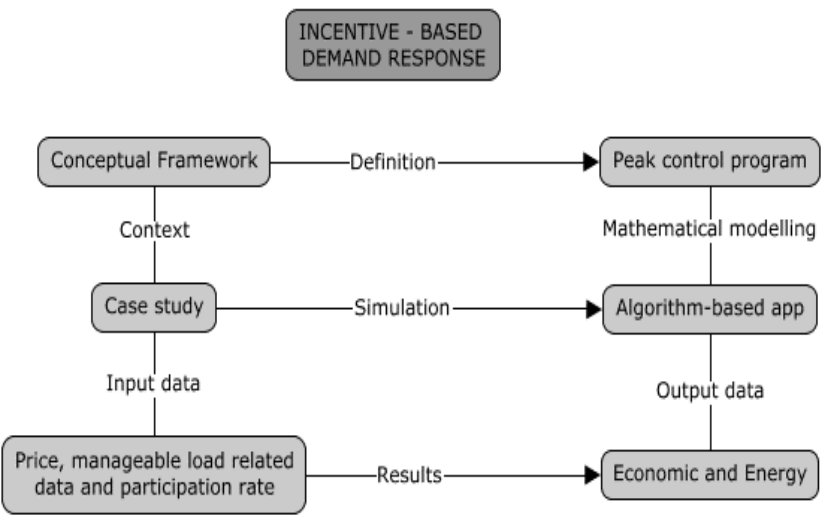

Fig. 1. Methodology diagram. Source: Author. Program: CMAPTOOLS.

\section{CONCEPTUAL FRAMEWORK}

This article applies the incentive-based demand response (DR) program whose advantages and disadvantages are listed in TABLE . According to [4], [5], [6], this technique can reduce the energy peaks of the user demand curves, by remunerating the aggregator with the scarcity price of the unplugged manageable load.
TABLE I

ADVANTAGES AND DISADVANTAGES OF INCENTIVE-BASED DR

Advantages Disadvantages

As the programs maintain growth, the partial control of most of the national demand can be achieved.

The disconnection of the demand is mandatory so the aggregator ensures a minimum amount of energy to offer.

It is not necessary to change the charging fee to a timebased system.

Ideal for demand-related peak reduction.

Ideal for cheap and reliable markets.
The strategies for the reduction of demand curve have an effect on a long term basis.

There is an involuntary participation of the provider in some programs.

It has more robust control system compared to the pricing strategy which makes it more expensive It is not ideal for overall flattening of the demand curve, i.e. reduce consumption The public needs to be convinced to participate in these programs.

\section{A. DR in peak demand control}

Incentive-based DR programs that include peak control operate by remotely cutting power supply when the system considers it to be convenient. This improves the reliability of the system during high-demand timeslots and negotiates beforehand the energy cuts through contracts or load reduction. Peak control programs can be implemented with voluntary cuts or automation-based mandatory cuts.

\section{B. Scarcity pricing}

These prices are established by the Colombian entity known as CREG (Energy and Gas Regulation Commission) which updates said prices each month [18] based on the variation of the fuel price index "New York Harbor Residual Fuel Oil 1\% Sulfur LP Spot Price". The scarcity price has a double purpose: it indicates when firm energy obligations are required "When the price surpasses the scarcity price" and it is also the price in which the supplied energy is compensated when said obligations are required [19]. In December 2018, the scarcity price stood at 0.16 dollars [20].

\section{User demand curve}

The demand curve, hourly or load-based, is a graphical representation of the electric demand throughout time [21]. According to international parameters, a minimum demand of $100 \mathrm{~kW}$ must be satisfied each hour in order to participate in demand response programs [22]. Hence, the typified demand curve is assessed as a case study for residential type consumers of middle socio-economic strata. The curve was defined by the GCEM research group from Universidad Distrital Francisco José de Caldas, based on consumption monitoring and polls answered by users [12]. Fig. 3 corresponds to the typified demand curve for a middle-class user. 


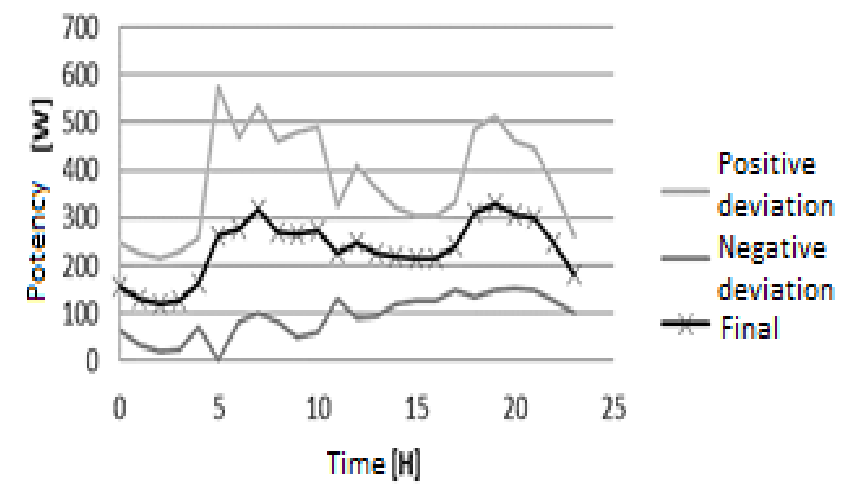

Fig. 2. User demand curve for a middle strata user in Bogotá. Source: GCEM Group Universidad Distrital Francisco José de Caldas.

Fig. 2 shows that the periods of higher consumption are between 6:00 and 9:00 and between 18:00 and 21:00.

\section{Manageable load}

In this work, a manageable load is defined as the amount of power to be disconnected in a DR program. In some countries such as Singapore [23], current legislation sets the manageable load at $10 \%$. For other authors [22], the manageable power percentage can reach 10,20 or even $30 \%$, which is more suitable to study the effects of DR programs. In Colombia, it is difficult to know the actual percentage of these types of loads since DR has been introduced quite recently. However, there is a precedent that serves as a reference point which is the "Apagar-paga" campaign that allowed the country to save $6.4 \%$ of energy in six weeks [2]. For the real scenario, it is recommended to use the $10 \%$ value for manageable loads. For academic and representative purposes, the load to be unplugged is set at $30 \%$ of the total load. In the case of dispatch, this value can reach $50 \%$ due to the existing timeframes (time period divisions throughout the day) which diminish the hours of the day when energy can be offered. There are four timeframes of 6 hours each and users can be present in two of them.

\section{CASE Study}

A case study consisting of 1000 users was proposed as a testing scenario. Their energy consumption behavior (demand curve) corresponds to the middle income strata of the city of Bogotá. The participation of users is made mandatory through contracts, thus the participation rate is $100 \%$. The program is called peak control since it consists on the direct reduction of high energy consumption during specific timeslots by $30 \%$ (manageable load). This energy disconnection is compensated based on the scarcity fee in dollars. The purpose is to analyze the energy-wise and economic advantages by applying the peak control program within a simulation. The peak control algorithm details the mathematical component of service operation, the application and the expected results of said service over the demand curve. The amount of disconnected energy and service cost (earnings from daily energy disconnection) are also defined.

\section{A. Peak control algorithm}

In this program, the input data for the aggregator are the scarcity price $(P e)$ in dollars (USD) and the manageable percentage $(\mathrm{Pg})$ given in p.u. For users, the input data are the demand curves $(D(h))$ where the independent variable is the hours (h) and the dependent variable is the power consumed by the user in $\mathrm{kW}$. Users are represented by the letter $(\mathrm{u})$. Peak hours are 6 to 9 am and 6 to 9 pm labelled with $\left(h p_{o n}\right)$ at the beginning of the timeframe and $\left(h p_{o f f}\right)$ when it is over.

After inserting all the input values, the total demand $\left(D_{T}(h)\right)$ is calculated as a function where the independent variable are the hours and the dependent variable is the joint demand from all user groups.

$$
D_{T}(h)=\sum_{i=1}^{u} D(h)
$$

The manageable load is computed as the total disconnection value of the service among all users (only during peak hours).

$$
C g(h)=P g * D_{T}(h) ; \quad h p_{\text {on }} \leq h \leq h p_{\text {off }}
$$

The applied service curve $C s(h)$ is derived from subtracting $C g(h)$ from $D(h)$ in each user and from the global form of the sum.

$$
C s(h)=D_{T}(h)-C g(h) ; \quad h p_{o n} \leq h \leq h p_{o f f}
$$

To calculate the constant value of the dispatched energy $(C g)$, the entire manageable load is summed up according to the peak hours in which each user was cut off from service.

$$
C g=\sum_{h p_{o n 1}}^{h p_{o f f 1}} C g(h)+\sum_{h p_{o f f 1}}^{h p_{o f f 2}} C g(h)
$$

The last calculation pertains to the constant value of the service cost $(C s)$ which is obtained by multiplying the dispatched energy $(\mathrm{Cg})$ with the scarcity price $(\mathrm{Pe})$.

$$
C s=P e * C g
$$




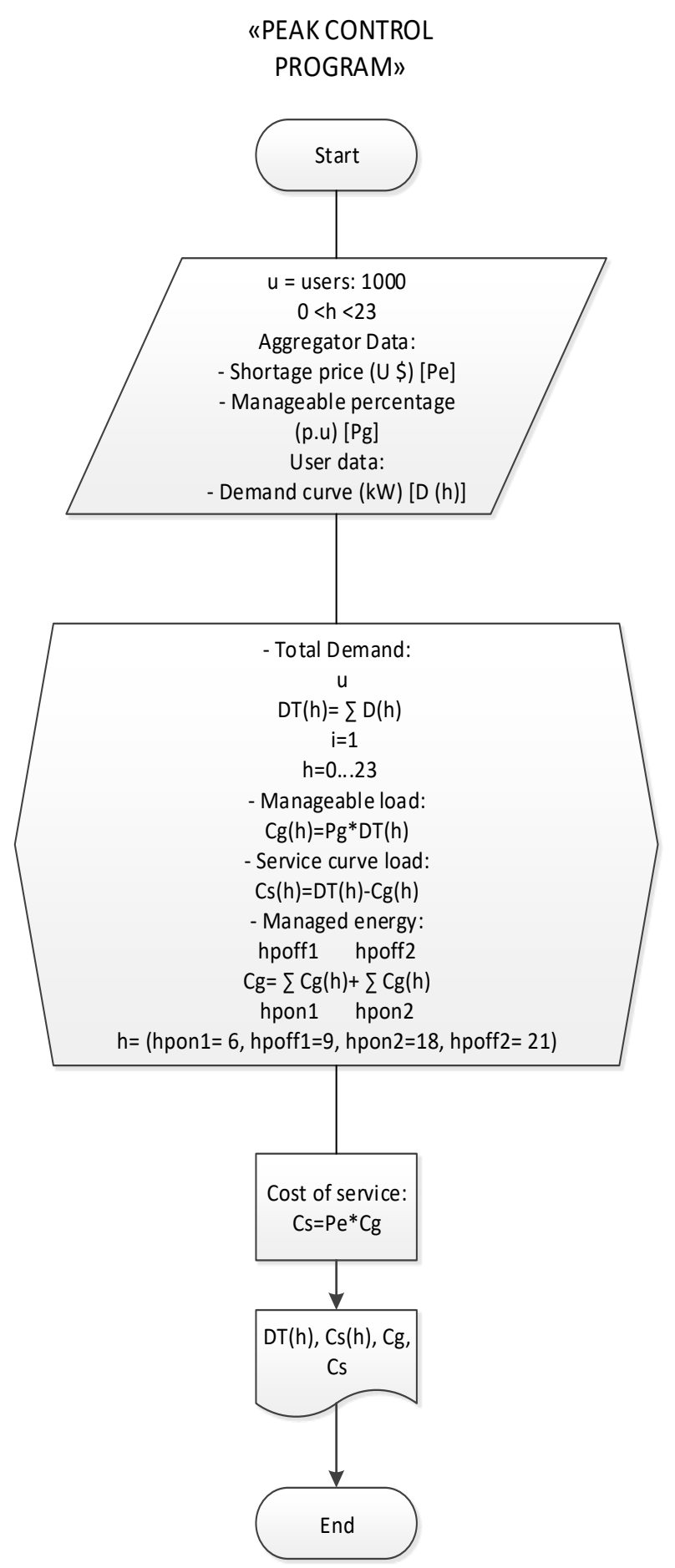

Fig. 3 corresponds to the algorithm of the main peak control program.

\section{B. DR program application for peak control}

Based on the proposed mathematic algorithm a software application was developed in MATLAB 2016 and Microsoft Excel 2013. It can simulate the demand response program for peak control. The input values received by the app are the scarcity price, the percentage of manageable load and the user participation rate. The output values are the initial and final demand curves (after the peak control program), dispatched energy and earnings of the aggregator from said energy.

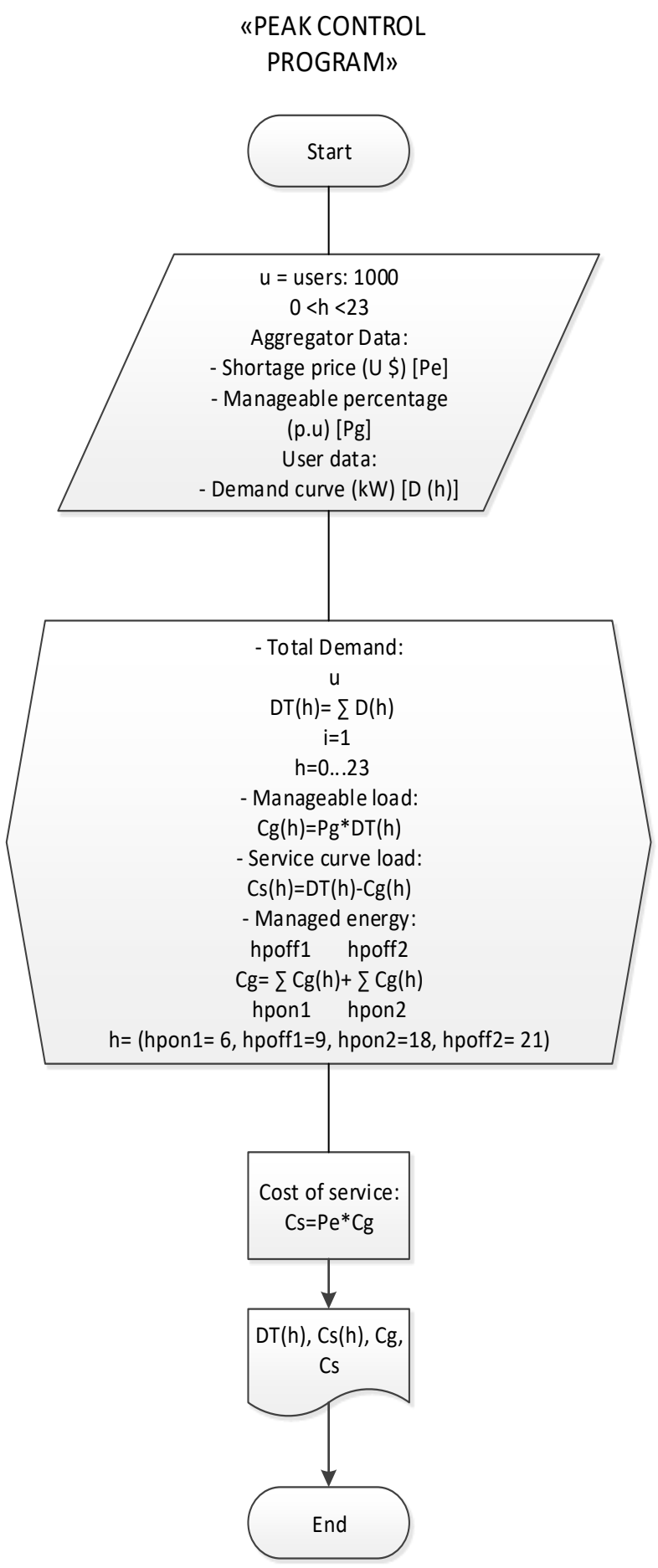

Fig. 3. Algorithm of the DR peak control program Source: Source: Author. Program: MICROSOFT VISIO. 


\section{RESULTS}

In this section, the values obtained with the application are discussed according to the proposed study and the simulation. TABLE shows the input values inserted in the application (price, manageable load and participation rate). Afterwards, the results are assessed in terms of energy (changes in the demand curve regarding peak reduction and daily disconnected energy) and earnings in dollars.

TABLE II

INPUT DATA OF THE APPLICATION

\begin{tabular}{cc}
\hline \hline Price & $0,15[\mathrm{USD}]$ \\
\hline Manageable load & $30 \%$ \\
Participation rate & $100 \%$ \\
\hline \hline
\end{tabular}

The simulation results of the proposed application are presented based on the input values. The application plots the initial and final curves and delivers the values of disconnected energy and the net value received by the aggregator from daily savings. The results are then grouped for energy-related and economic analysis.

The results of the peak control program according to the case study can be evidence by comparing Fig. 4 with Fig. 5. The latter shows the peak disconnection, the disconnected energy and the changes in the demand curve. Fig. 6 shows a daily disconnected energy of $711,812 \mathrm{kWh}$ directly from the application, valued with a daily scarcity price of 106,722 USD.

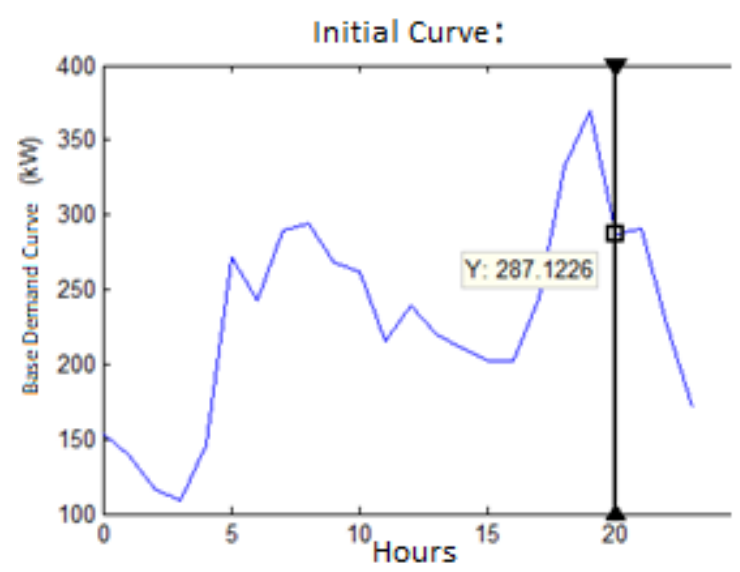

Fig. 4. Initial plot of 1000 users before the application of the DR program. Source: Demand response application, elaborated by author.

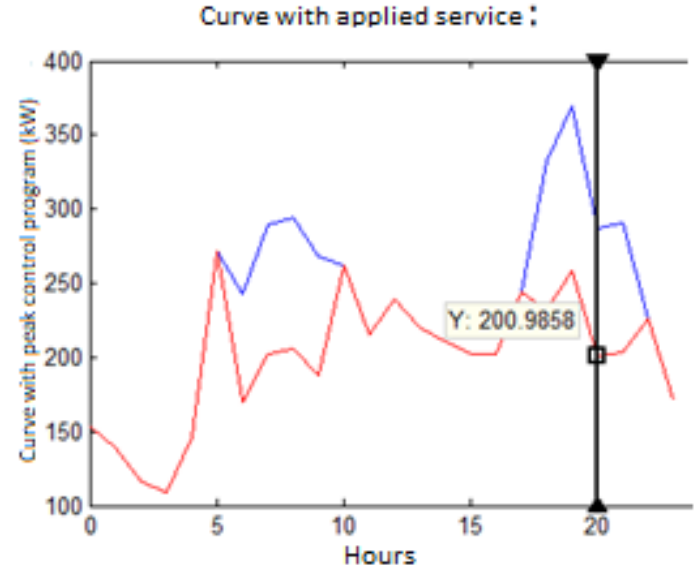

Fig. 5. Final plot of 1000 users after the application of the DR program. Source: Demand response application, elaborated by author.

\section{Power Disconnected (kWh): $\quad 711.812$ \\ Earnings (USD): $\quad 106.772$}

Fig. 6. Results of the peak control program. Source: Demand response application, elaborated by author.

TABLE III shows the results obtained including the input values of the disconnected energy in $\mathrm{kWh}$, the earnings per day in dollars and the behavioral change in the user consumption curve for the described case study.

TABLE III.

PEAK CONTROL PROGRAM CONSOLIDATED RESULTS.

\begin{tabular}{|c|c|}
\hline Disconnected energy & $711.812[\mathrm{kWh}]$ \\
\hline Earnings & $106.722[\mathrm{USD}]$ \\
\hline $\begin{array}{c}\text { Behavioral change } \\
\text { with the DR program }\end{array}$ & $\begin{array}{c}\text { Elimination of energy peaks during } \\
\text { higher consumption timeframes. }\end{array}$ \\
\hline
\end{tabular}

\section{ANALYSIS OF RESULTS}

A demand response program structure is proposed that can be applied on an international scale given that it uses incentives during peak hours to directly reduce consumption. This solution is viable from a financial standpoint and can improve the quality of energy. A normative study of the country must be considered for the applicability of this type of program, thus allowing the adaptation of theoretical concepts in the practical field.

The value of the net daily income of the aggregator due to the energy disconnection $(711.812 \mathrm{kWh})$, remunerated with a scarcity price of 106,722 USD. If this value is multiplied by the number of days in a year then the annual net income would be $38.953,53$ dollars which is high given that the simulation only included 1000 users. Hence, the demand response program is clearly profitable in Colombia. There are additional benefits such as saving energy in Colombian households and automated houses (which is a requirement to apply the peak control program), while improving the comfort of users. The economic benefits of an energy network with higher quality 
should also be considered, represented by a demand curve without consumption peaks.

The value of the demand response strategy is mainly evidenced in the linearization of the demand curve by cutting the consumption peaks. This causes the network to become more stable and less dependent on fossil fuel energy sources since thermal generation is used to cover up energy peaks. The resulting energy matrix is more environmentally friendly. Another advantage in terms of energy is the direct reduction of energy consumption with a daily saving of $711,812 \mathrm{kWh}$, which is an annual saving of 260 MWh. This energy saving allows a better distribution of the resources for generation and energy transportation. Therefore, the network is more flexible to supply energy in case of scarcity due to natural causes.

\section{CONCLUSION}

The proposed program "Energy consumption modelled based on the middle-level strata in the city of Bogotá" with 1000 users and a manageable load of $30 \%$ (case study), delivers an annual energy disconnection of $260 \mathrm{MWh}$ with 1000 users. The annual income for the aggregator is 38953,53 dollars, benefits for users (automation and energy savings) and benefits for the network (linear demand curve and better energy management). These results lead to conclude that the incentive-based DR peak control program is viable from an economic and energy standpoint and can be applied in international contexts.

\section{REFERENCES}

[1] Instituto nacional de tecnologias agropecuarias, "Climayagua", 2907 2019. [En línea]. Available: http://climayagua.inta.gob.ar/que_es_el_fenomeno_el_ni\%C3\%B1o.

[2] Ministerio de minas y energia, "Apagar paga," Ministerio de minas y energia, Bogota D.C., 2016.

[3] E. M. Klaassen, R. V. Gerwen, J. Frunt y J. Slootweg, "A Methodology to assess demand response benefits from a system perspective: A Dutch Case Study," Util Policy, vol. 44, pp. 25-37, 2017. DOI: 10.1016/j.jup.2016.11.001

[4] G. Marulanda, "Impacto de un programa de respuesta de la demanda electrica en el sector de gas natural," Universidad Tecnologica de pereira, Pereira, 2014. http://hdl.handle.net/11059/4649

[5] M. P. G. J. S. L. Rodriguez Mercedes, "Gestión activa de la demanda para una Europa más eficiente," Anales de mecanica y electricidad, 2013. http://hdl.handle.net/11531/4978

[6] A. Nieto, "El papel de la gestion de la demanda en la eficiencia de mercado mayorista de electricidad," NERA Economic Consulting, Madrid, 2012.

[7] M. Albadi y E. El-Saadany, "Demand response in electricity markets: An overview," IEEE Power Eng. Soc Gen Meet. PES, pp. 1-5, 2007 DOI: 10.1109/PES.2007.385728

[8] G. Schuh, U. Brandenburg y Y.Liu, "Evaluation of Demand Response Actions in Production Logistics," Procedia CIRP, vol. 29, pp. 173-178, 2015. https://doi.org/10.1016/j.procir.2015.02.161

[9] S. Aman, M. Frincu, C. Chelmis, M. Noor, Y. Simmhan y V. Prasanna, "Prediction Models for Dynamic Demand Response," pp. 338-343, 2015.

DOI: 10.1109/SmartGridComm.2015.7436323
[10] P. Palensky y D. Dietrich, "Demand side management: Demand response, intelligent energy systems, and smart loads," IEEE Trans. Ind. Informatics, vol. 7, $\mathrm{n}^{\circ} 3$, pp. 381-388, 2011. DOI: $10.1109 /$ TII.2011.2158841

[11] L. A. Arias, F. Ruiz, D. Patiño, E. Rivas y F. Santamaria, "Proposal of operation for the demand response integrating agent in electrical distribution networks," IEEE 3rd Colomb. Conf. Autom. Control (CCAC), Caer 2017, 2017. DOI: $10.1109 / C C A C .2017 .8276476$

[12] A. Vega, "Gestion de la energia electrica domiciliaria con base en la Gestion Activa de la Demanda," Tesis Doctoral. Universidad Distrital Francisco José de Caldas, vol. 1, p. 132, 2017.

[13] T. Shin-Ching, T. Yi-Hen y C. Tsung-Hui, "Communication-Efficient Distributed Demand Response: A Randomized ADMM Approach," IEEE, 2017. DOI: 10.1109/TSG.2015.2469669

[14] M. Abolfazl, C. Cañizares y K. Bhattacharya, "Optimal Demand Response for Distribution Feeders with Existing Smat Loads," IEEE, 2017. DOI: 10.1109/TSG.2017.2686801

[15] Z. Wang y P. Raman, "Optimal Residencial Demand Response for Multiple Heterogeneous Homes with Real-Time Price Prediction in a Miltiagent Framework," IEEE, 2017. DOI: 10.1109/TSG.2015.2479557

[16] A. Maytham, M. Azah, H. Shareef, R. Homod y J. Abd, "Artificial neural network based controller for home energy management consideing demand response event," IEEE, 2016.

DOI: 10.1109/ICAEES.2016.7888097

[17] L. K. Panwar, S. R. Konda, A. Verma , B. K. Panigrahi y R. Kumar, "Demand response aggregator coordinated two-stage responsive load scheduling in distribution system considering customer behavior," IEEE, 2017. DOI:10.1049/IET-GTD.2016.1165

[18] XM "Lista de precios cargo por confiabilidad", "Lista de precios cargo por confiabilidad," XM, 2017.

[19] XM "Obligaciones energia firme", "Obligaciones energia firme," Cargo por confiabilidad, 2017.

[20] XM, "Precio de escasez,” Indicadores, 2018.

[21] P. Lopez, “¿QUÉ ES LA CURVA HORARIA?,” Twenergy, 2015.

[22] T. T. Chandira Prabhu, S. Sankara N, V. Githanjali y S. Sindhu, "Demand Response:A Decisive Approach for," IEEE, India, 2011. DOI:10.1109/ISET-India.2011.6145381

[23] Y. Wenxian, C. Chin, T. Tat, L. Xiang y R. Yu, "An Overview and evaluation on demand response program in Singapore electricity market," Infocomm Research, Singapore, 2014.

https://oar.a-star.edu.sg/jspui/handle/123456789/1615 


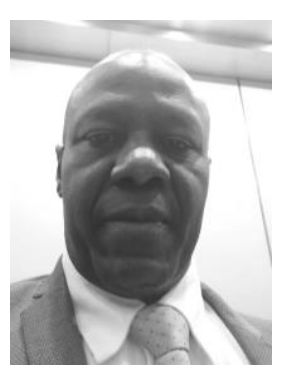

Edwin Rivas Trujillo. He received his Engineering degree from Universidad del Valle in 1991 and his Master's degree in electric power generation from the same university in 1997. He then obtained a Master's degree (2007) and $\mathrm{PhD}$ (2009) in Electrical, Electronics and Automatic Engineering from University Carlos III in Madrid.

He served in the public sector as an intervention Engineer in the municipal companies of Cali E.I.C.E. E.S.P. between 1994 and 2001. He currently works as a tenured teacher at Universidad Distrital Francisco Josè de Caldas and leads the research group GCEM "Group of Electromagnetic Compatibility and Interference". He has lead different research projects as well as undergraduate, postgraduate and doctorate-level theses. His areas of interest include Distributed Energy Resources (DER) specifically in demand response, distributed generation and energy storage, renewable energies, energetic efficiency, energy markets, electromagnetic compatibility and interference, power systems and transformers.

ORCID: https://orcid.org/0000-0003-2372-8056

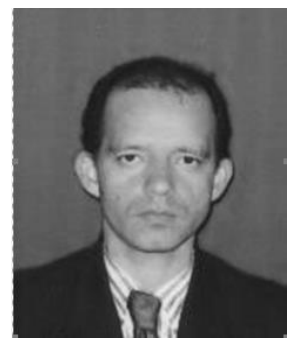

Luis Alejandro Arias Barragán. He received his degree in Electromechanical Engineering from the Kharkov Polytechnic Institute in Ukraine in 1996 and his Master's degree in Electrical Engineering from the same university in 1997. He then obtained a Master's degree in Information Sciences and Telecommunications from Universidad Distrital Francisco Josè de Caldas - Colombia in 2009; and a PhD in Engineering from the same university in 2019.

He worked in the public sector as an Electromechanical Engineer in the area of hydroelectric machinery design. In the academic sector he works as a research professor at Universidad Autónoma de Colombia and Universidad Distrital Francisco José de Caldas. His published work includes "A Review and Analysis of Trends Related to Demand Response" (2018) in the MDPI journal; "Analysis of the example of transient stability regions of multi-machines" (2018); "Propuesta de modelo de Gestión para redes eléctricas con Generación Distribuida a través de Unidades de Medición Fasorial" (2017). His areas of interest include distributed energy resources (DER) specifically in demand response, distributed generation and energy storage, renewable energies, energy efficiency and energy markets.

ORCID: https://orcid.org/0000-0001-9264-4943

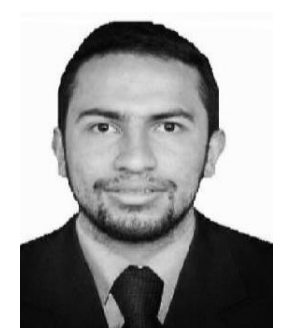

Víctor Andrés Hernández Arias. He received his Electrical Engineering degree from Universidad Distrital Francisco José de Caldas, Bogotá in 2017 and his postgraduate degree in engineering project management from the same university in 2019.

From 2017 to 2019, he worked in the private sector as an Electrical Engineer in the areas of construction, renewable energies and auditing. In 2018, he was the co-author of the article "A Review and Analysis of Trends Related to Demand Response" published in the MDPI journal. His areas of interest include distributed energy resources (DER) specifically in energy resources, demand response, distributed generation and energy storage, renewable energies, energy efficiency and energy markets.

ORCID: https://orcid.org/0000-0002-0326-9537 . 